\title{
DROPLET SIZE OF VIROCIDE DISINFECTANT LIQUID FROM VORTEX INJECTOR SPRAYER UNDER DIFFERENT OPERATING CONDITIONS
}

\author{
Boris Ivanov, Bulat Ziganschin, Andrey Dmitriev, Gennady Pikmullin, Anas Mustafin \\ Kazan State Agrarian University, Russia \\ littab@mail.ru, zigan66@mail.ru, avd-work@mail.ru
}

\begin{abstract}
The successful development of the livestock industry directly depends on veterinary and sanitary wellbeing. There are different types of disinfectants on the market, but their use in the same doses or overuse rates leads to increasing antimicrobial resistance of microorganisms. This fact can cause the appearance of more robust microorganisms, increase economic costs, and lead to an environmental disaster in the livestock sector. The disinfection efficiency depends on many factors, such as the concentration and temperature of the disinfectant, exposure time, room air temperature, the purity of the treated surface, and the sprayers' technical capabilities. A laboratory setup has been developed to simulate the disinfection process using a new sprayer under various operating conditions. A measuring unit was developed to conduct studies of the dispersion analysis of the spray. According to the experimental data, graphical dependencies are constructed showing the effect of the working pressure in the vortex device on heating of compressed air at the inlet to the sprayer, the degree of heating of the disinfectant liquid by compressed hot air, and the kinematic viscosity of the disinfectant liquid versus its temperature. The droplet sizes at different conditions of the sprayer operation are obtained. A thermomechanical (dispersion-condensation) method of applying the disinfectant liquid is proposed to increase veterinary and sanitary measure efficiency. The method's principle is based on breaking up the liquid into fine particles and heating them from a hot gas flow kinetic energy. Based on the obtained experimental data, the operating conditions of the developed vortex injector sprayer were determined to satisfy specific veterinary and sanitary requirements.
\end{abstract}

Keywords: disinfection, sprayer, pressure, droplet size.

\section{Introduction}

The modern conception of science and technology development in crop and livestock production covers many different tasks, such as improving the efficiency, reliability, and safety of process operations and implementing effective measures for veterinary and sanitary protection of agricultural rooms and equipment. One solution to these problems is connected with the development of technical devices with dispersed gas-liquid flows. However, the research complexity of dispersed flows determined by interfacial and intercomponent pattern formation and the effect of geometrical and working parameters limits the study of fluid dynamics and heat transfer processes in spray devices and apparatuses [1].

The study of sprayers includes numerous measurement techniques and mathematical models providing recommended practices for calculating and improving their efficiency. Besides, experimental papers describe laboratory measurements of the droplet size, and theoretical studies propose droplet distribution functions by number, size, and mass [2]. When dispersing liquids by known sprayers, a polydisperse droplet system is formed, determined by the number and degree of broke-up droplets in the spray [3]. Size analysis methods for disinfectant liquids depending on the flow rate, direction, and velocity of droplets have been studied earlier [4-6]. However, as far are not well investigated: changing the droplet size during the spray interaction with the environment, dispersion process due to heating the liquid, and injecting the droplets with the gas flow.

The purpose of this work is to investigate the effect of the physical and mechanical parameters of the new vortex injector sprayer on the characteristics of the disinfectant spray under various operating conditions.

\section{Materials and methods}

From previous studies [6-9], as the crucial factors affecting the spray dispersion, the following parameters were determined:

1. Design features of the sprayer;

2. Working pressure of the spray liquid $(P, \mathrm{MPa})$;

3. Temperature of the working liquid $\left(T,{ }^{\circ} \mathrm{C}\right)$;

4. Kinematic viscosity of the working liquid $\left(v, \mathrm{~m}^{2} \cdot \mathrm{s}^{-1}\right)$. 
Fig 1 presents a disinfectant laboratory setup developed to evaluate these parameters' effect on the spray dispersion.

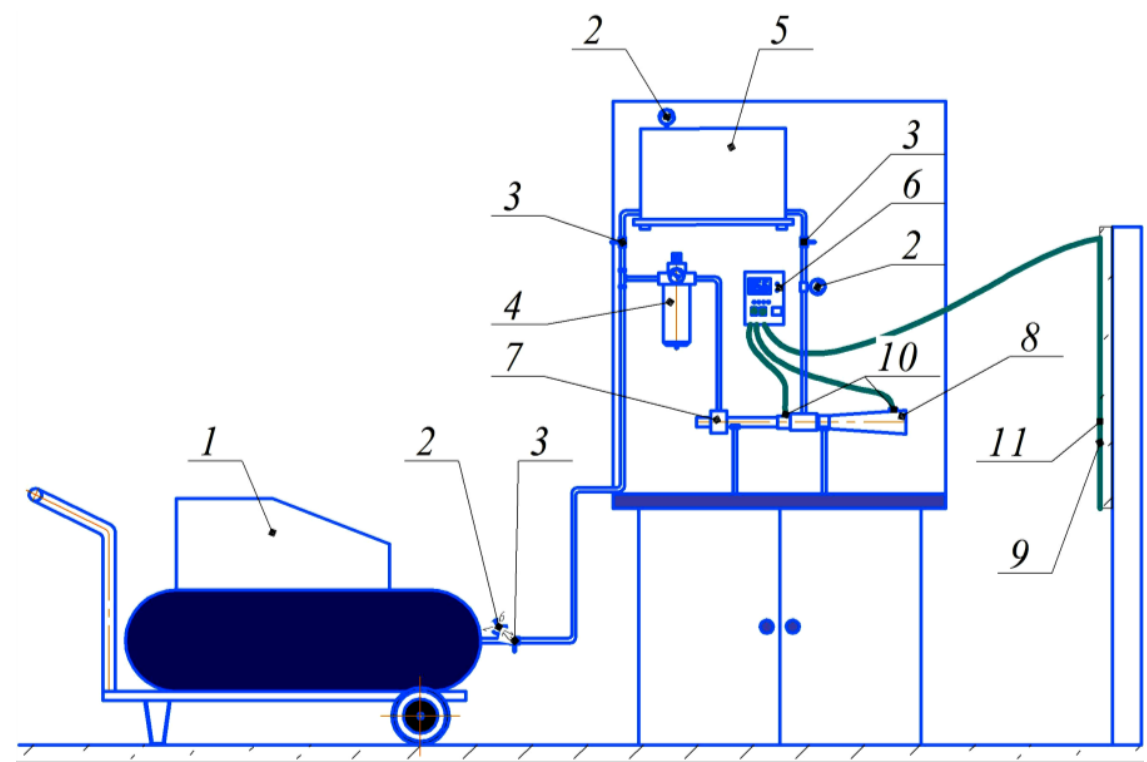

Fig. 1. Laboratory setup: 1 - compressor; 2 - manometer; 3 - valve; 4 - dewatering tank; 5 - mixing tank; 6 - universal meter-regulator; 7 - vortex tube; 8 -vortex injector sprayer; 9 - treated surface; 10 - temperature sensors; 11 - rotameter; 12 - water meter

The experimental setup consists of the vortex injector sprayer 8 and systems for supply, measurement, and control of the disinfectant liquid and compressed air flows. The disinfectant system includes a $0.12 \mathrm{~m}^{3}$ mixing tank 5 made of stainless steel, compressor 1, and pipelines. Through the pipeline, the working liquid is delivered to the sprayer 8 . Compressed air from the compressor 1 is supplied to a vortex tube 7 via a dewatering tank 4. The rotameter 11 and SGV-15 water meter 12 are designed to measure compressed air and working liquid flow rates, respectively. Manometer 2 is used to control the working pressure of liquid and compressed air. The valve 3 controls the compressed air supply. Thermocouples 10 (with an Owen-2TRM110 meter-regulator) measure the air temperature supplied through the vortex tube 7 at the inlet and the gas-liquid flow temperature at the outlet of the sprayer.

A series of experiments were carried out using the developed injector-type sprayer (Figure 2) with a set of geometrical parameters according to Table 1 to evaluate the effect of its design parameters on the dispersion of droplets, heat transfer from heated compressed air to the working liquid, density and uniformity of disinfectant solution coating.

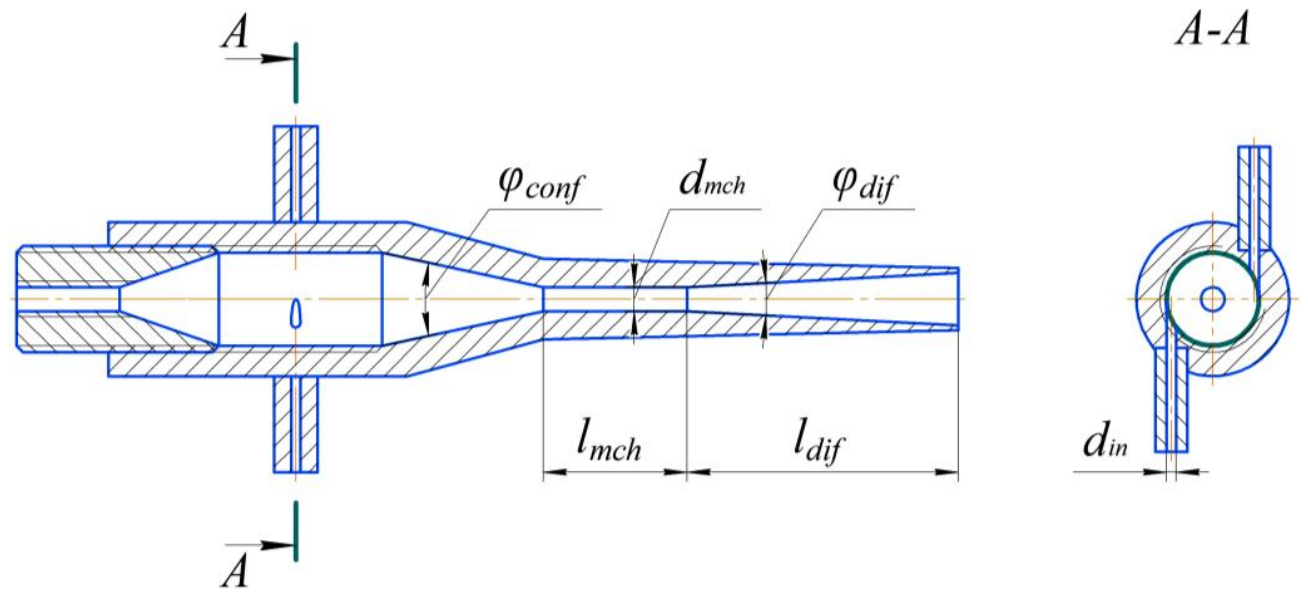

Fig. 2. Scheme of vortex injector sprayer: $\varphi_{c o n f}-$ cone angle of the confuser; $\varphi_{d i f}-$ cone angle of the diffuser; $l_{m c h}$ - length of the mixing chamber; $l_{d i f}-$ length of the diffuser chamber; $d_{m c h}$ - diameter of the mixing chamber; $d_{i n}$ - diameter of the tangential liquid supply channel 
Geometrical parameters of the vortex injector sprayer

\begin{tabular}{|c|c|c|}
\hline Symbol & Unit & Value \\
\hline$\varphi_{\text {conf }}$ & degrees & $24 \pm 1$ \\
\hline$\varphi_{\text {dif }}$ & degrees & $6 \pm 1$ \\
\hline$l_{m c h}$ & $\mathrm{~mm}$ & 31 \\
\hline$l_{\text {dif }}$ & $\mathrm{mm}$ & 58 \\
\hline$d_{m c h}$ & $\mathrm{~mm}$ & 5 \\
\hline$d_{\text {in }}$ & $\mathrm{mm}$ & 1 \\
\hline
\end{tabular}

The experimental setup allows simulating the disinfection of treated surfaces by spraying liquid chemicals. In order to determine the droplet size of the spray, it is possible to vary the parameters of the disinfectant liquid: working pressure - from 0 to $0.6 \mathrm{MPa}$ and temperature - from 0 to $80{ }^{\circ} \mathrm{C}$ ). A measuring unit (Figure 3) consists of a personal computer 1, a Micromed-3 (version 3-20) digital microscope 2, the Goryaev's counting chamber as the slide 3 . The counting chamber is a specific slide glass with a microscopic grid applied to it (Figure 4). The Goryaev's chamber can directly count the number of deposited droplets on the slide and determine their size [10].

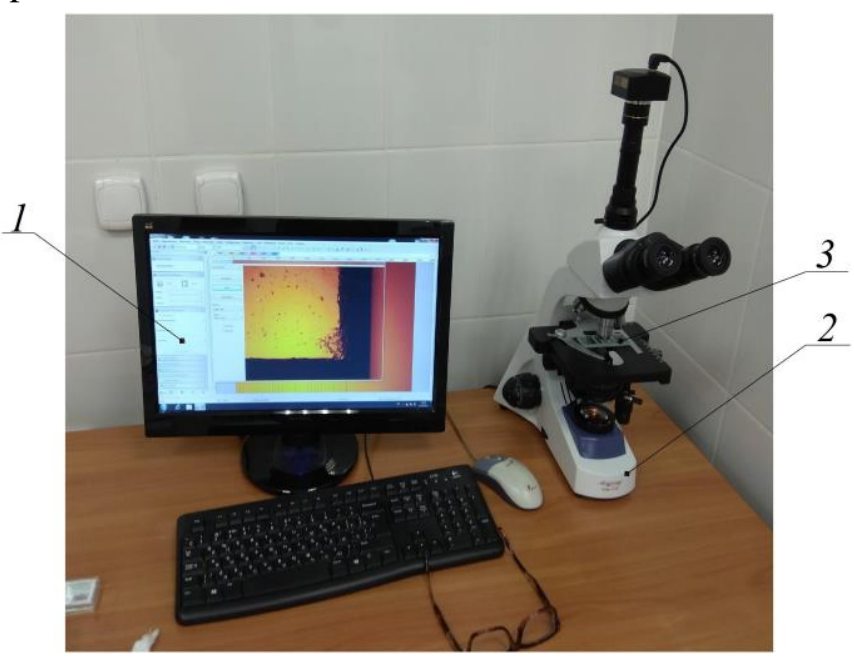

Fig. 3. Measuring unit for dispersion analysis: 1 - computer; 2 - microscope; 3 - slide glass with Goryaev's counting chamber
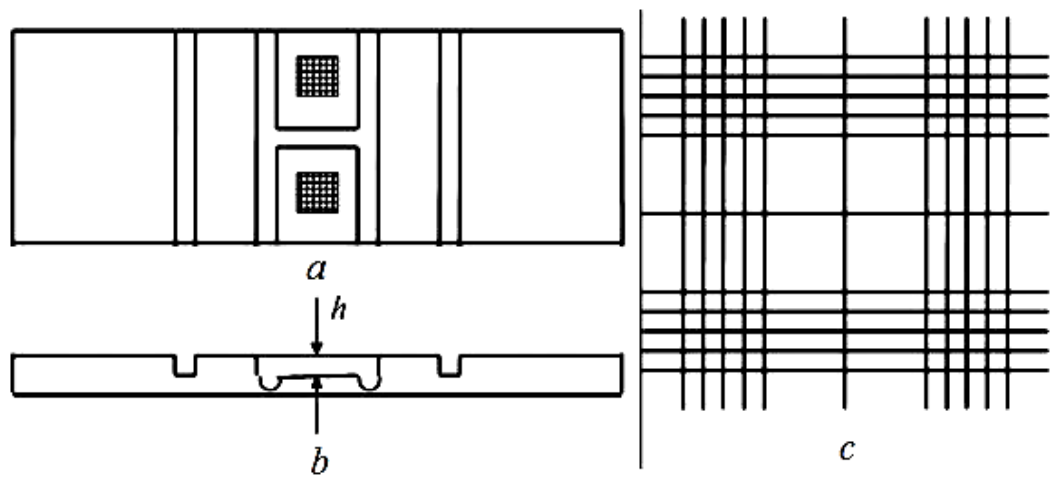

Fig. 4. Structure of Goryaev's counting chamber: $a$ - top view; $b$ - side view; $\mathrm{c}$ - grid layout; $h$ - depth

Before the experiments the slide glass 3 is coated with a layer of glycerol to create an immersion medium. Under the sprayer's set operating conditions, the immersion-layer slide was moved uniformly across the aerosol spray, normally to its axis at a distance of $380 \mathrm{~mm}$. Then the glass was placed on the microscope stage, and the droplets of the sprayed liquid were analyzed. The obtained images were transmitted to a personal computer, where using the Levenhuk ToupView software (graphic object 
detection), the size of the deposited drops was determined. Levenhuk ToupView is designed for data analysis, including mathematical and programming methods of experimental data processing.

During the vortex injector sprayer study at the experimental setup, the compressed air working pressure in the vortex pipe varies from $0.1 \mathrm{MPa}$ to $0.6 \mathrm{MPa}$ on a $0.05 \mathrm{MPa}$ pitch; as for liquid in the sprayer, it is constant $(0.3 \mathrm{MPa})$. Virocide disinfectant (CID LINES, $\left.\mathrm{NV} \cdot \mathrm{s}^{-1} \mathrm{~A}\right)$ was used as the working liquid.

\section{Results and discussion}

The experimental results manifested that an increase in the hot gas temperature at the vortex tube outlet $[11,12]$ occurs, when the pressure of the compressed air in the vortex tube goes up. Table 2 shows the obtained values of heated gas at the hot stream outlet at various inlet pressures.

Experimental values of the hot gas under different pressure

Table 2

\begin{tabular}{|c|c|}
\hline $\begin{array}{c}\text { Compressed air pressure in the } \\
\text { vortex tube }\left(\boldsymbol{P}_{\text {in }}\right), \text { bar }\end{array}$ & $\begin{array}{c}\text { Hot gas temperature at the } \\
\text { vortex tube outlet }(\boldsymbol{T}),{ }^{\circ} \mathbf{C}\end{array}$ \\
\hline 0.10 & 20 \\
\hline 0.15 & 24 \\
\hline 0.20 & 29 \\
\hline 0.25 & 34 \\
\hline 0.30 & 42 \\
\hline 0.35 & 59 \\
\hline 0.40 & 75 \\
\hline 0.45 & 86 \\
\hline 0.50 & 98 \\
\hline 0.55 & 110 \\
\hline 0.60 & 120 \\
\hline
\end{tabular}

Table 1 indicates that the pressure of compressed air in the vortex tube significantly affects the hot gas capacity. Based on the data in Table 2, a $P_{\text {in }}-T$ curve is plotted, showing the linear dependence of these parameters.

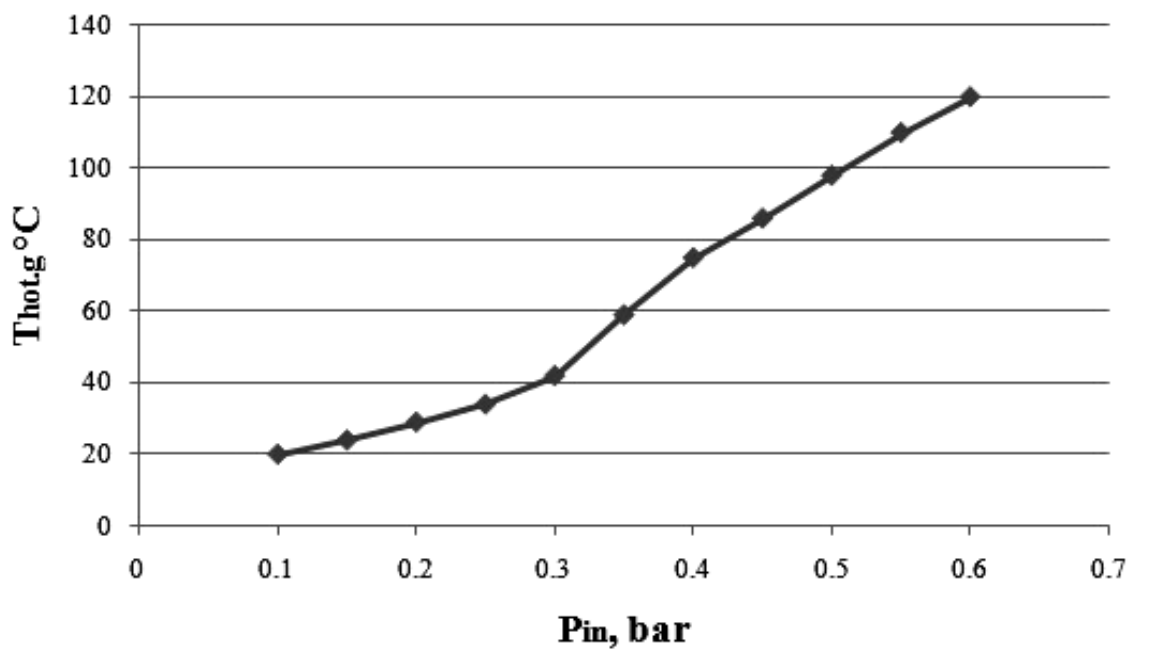

Fig. 5. Dependence of hot gas temperature versus pressure of compressed gas in the vortex tube

The vortex injector sprayer is inherently a heat exchanger - atomizer for heating and dispersing the disinfectant liquid. Under laboratory conditions, the degree of heating of the sprayer disinfectant liquid at different temperatures of the hot gas at the sprayer inlet was determined (Table 3). The initial temperature of the disinfectant is $20^{\circ} \mathrm{C}$. 
Experimental values of hot gas and liquid temperatures

\begin{tabular}{|c|c|}
\hline $\begin{array}{c}\text { Hot gas temperature at the sprayer } \\
\text { inlet }\left(\text { Thot }_{\text { }}\right) \mathbf{~}^{\mathbf{}} \mathbf{C}\end{array}$ & $\begin{array}{c}\text { Hot disinfectant liquid temperature at the } \\
\text { sprayer outlet, }{ }^{\mathbf{}} \mathbf{C}\end{array}$ \\
\hline 20 & 20.0 \\
\hline 24 & 20.2 \\
\hline 29 & 21.3 \\
\hline 34 & 24.9 \\
\hline 42 & 29.88 \\
\hline 59 & 42.3 \\
\hline 75 & 55.1 \\
\hline 86 & 62.7 \\
\hline 98 & 70.56 \\
\hline 110 & 76.8 \\
\hline 120 & 80.2 \\
\hline
\end{tabular}

Based on the obtained data, the hot disinfectant liquid temperature is plotted against the compressed air temperature at the inlet to the sprayer (Figure 6).

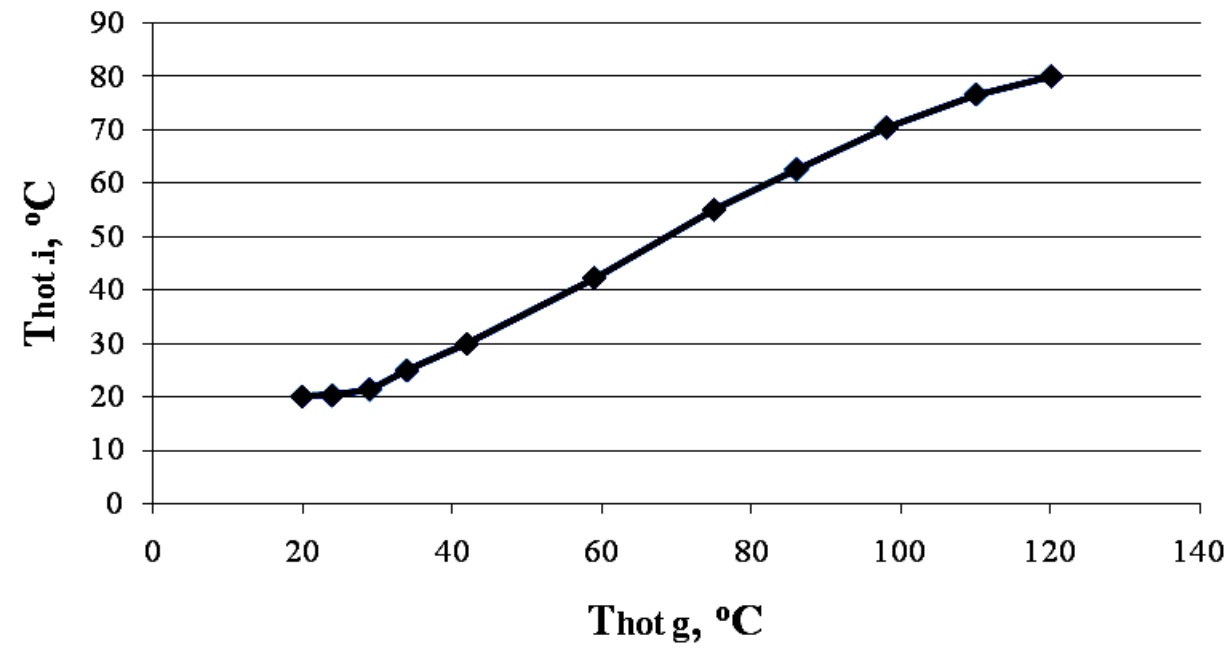

Fig. 6. Liquid-gas temperature dependence

In the dispersion process, the liquid viscosity significantly affects the size of the resulting droplets [13]. With increasing temperature, the physicochemical properties of liquids (kinematic viscosity and surface tension) decrease [14], since the adhesion forces between the molecules weaken [15; 16]. Therefore, it is easier to break up the heated liquid into small particles by spraying and obtain a monodisperse aerosol. Table 4 shows the experimental results of the investigation of the temperature effect on the physicochemical parameters of the Virocide disinfectant.

Table 4

Experimental values of the temperature effect on the kinematic viscosity of the Virocide disinfectant

\begin{tabular}{|c|c|}
\hline $\boldsymbol{T}_{\text {hot.l }} \boldsymbol{}^{\mathbf{o}} \mathbf{C}$ & $\boldsymbol{v} \cdot \mathbf{1 0}^{\mathbf{6}} \mathbf{~}^{\mathbf{2}} \cdot \mathbf{s}^{\mathbf{1}}$ \\
\hline 0 & 1.789 \\
\hline 20 & 1.005 \\
\hline 40 & 0.649 \\
\hline 60 & 0.471 \\
\hline 80 & 0.363 \\
\hline 100 & 0.293 \\
\hline 120 & 0.249 \\
\hline
\end{tabular}


Table 4 indicates that the kinematic viscosity of the Virocide disinfectant liquid is close to water. A graph of the liquid kinematic viscosity dependence on its various temperatures is plotted (Figure 7).

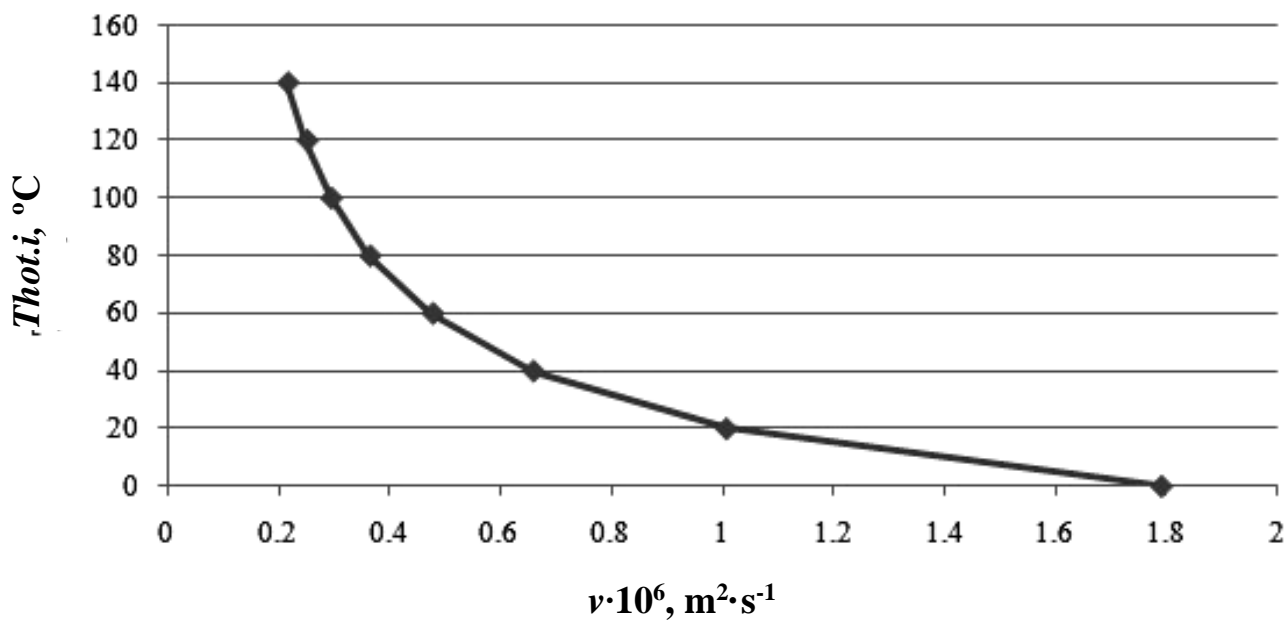

Fig. 7. Temperature-kinematic viscosity dependence on the disinfectant liquid

Using the measuring unit for examining the droplet size of the spray dispersion, we obtained images of formed liquid droplets at the working pressures of $0.4,0.5$, and $0.6 \mathrm{MPa}$ in the system (Figure 8).

a)

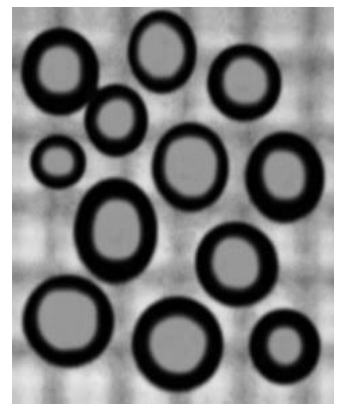

b)

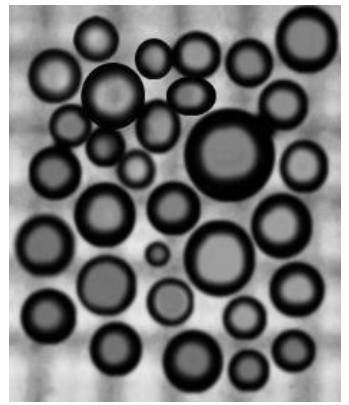

c)

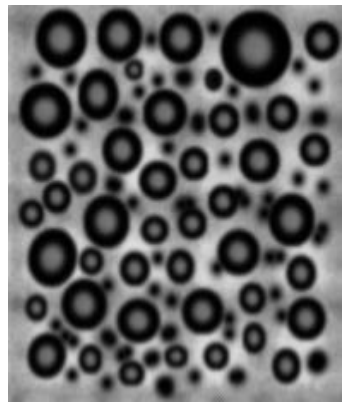

Fig. 8. Images of droplets under different working pressure: $\mathrm{a}-0.4 \mathrm{MPa} ; \mathrm{b}-0.5 \mathrm{MPa} ; \mathrm{c}-0.6 \mathrm{MPa}$

Using the Levenhuk ToupView software, the deposited droplet sizes per $1 \mathrm{~cm}^{2}$ were received at various operating conditions of the vortex injector sprayer (Table 5).

Table 5

Experimental values of the deposited droplet sizes

\begin{tabular}{|c|c|c|c|c|c|}
\hline \multicolumn{2}{|c|}{$\boldsymbol{P}_{\text {in }=4} \mathbf{4}$ MPa } & \multicolumn{2}{c|}{$\boldsymbol{P}_{\text {in }}=\mathbf{5} \mathbf{M P a}$} & \multicolumn{2}{c|}{$\boldsymbol{P}_{\text {in }}=\mathbf{6}$ MPa } \\
\hline$n, \mathrm{pcs}$ & $D_{\text {aver }}, \mu \mathrm{m}$ & $n, \mathrm{pcs}$ & $D_{\text {aver }}, \mu \mathrm{m}$ & $n, \mathrm{pcs}$ & $D_{\text {aver }}, \mu \mathrm{m}$ \\
\hline 96 & 20 & 247 & 20 & 404 & 20 \\
\hline 74 & 50 & 206 & 50 & 220 & 50 \\
\hline 107 & 80 & 194 & 80 & 120 & 80 \\
\hline 120 & 110 & 156 & 110 & 60 & 110 \\
\hline 86 & 140 & 110 & 140 & 27 & 140 \\
\hline 79 & 170 & 64 & 170 & 16 & 170 \\
\hline 54 & 200 & 25 & 200 & 5 & 200 \\
\hline 40 & 230 & 14 & 230 & - & 230 \\
\hline 24 & 260 & 3 & 260 & - & 260 \\
\hline 11 & 290 & - & 290 & - & 290 \\
\hline 7 & 320 & - & 320 & - & 320 \\
\hline
\end{tabular}

Figure 9 graphically presents the dependence of the average diameter and the number of droplets under various operating conditions of the vortex injector sprayer. 


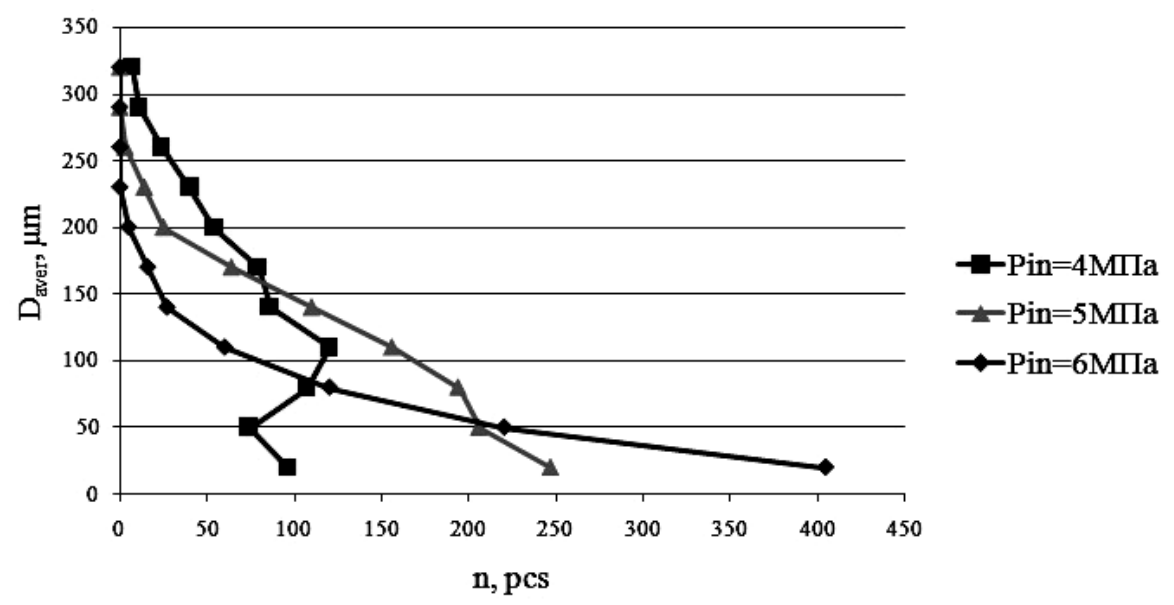

Fig. 9. Average diameter and number of droplets at different working pressure of the sprayer

Results revealed that the sprayer working at $P_{\text {in }}=4 \mathrm{MPa}$ is suitable for surface treatment by wetting a disinfectant, whereas at $P_{i n}=5 \mathrm{MPa}$ and $P_{\text {in }}=6 \mathrm{MPa}-$ for aerosol disinfection. The droplet size and temperature of the aerosol directly provide its penetrating capacity, causing an increase in the disinfectant chemical activity.

One of the essential conditions for veterinary and sanitary work conditions is developing highperformance technical devices for dispersing certain disinfectants to develop science-based biochemical technologies for processing premises and equipment.

\section{Conclusions}

1. The developed disinfectant setup with the measuring unit can investigate the droplet size of the spray from the new vortex injector device and obtain reliable experimental data affecting the quality of dispersing disinfectants.

2. Dependencies of the operating parameters for the vortex injector sprayer are determined, which provide the formation of spray with a particular droplet size to satisfy specific veterinary and sanitary requirements, in particular, it was found that the disinfectant wets the surface at the compressed air pressure $P_{i n}=4 \mathrm{MPa}$, while aerosol disinfection occurs at the pressure $P_{\text {in }}=5 \mathrm{MPa}$ and $P_{\text {in }}=6 \mathrm{MPa}$.

\section{References}

[1] Borujerdi A.N., Kebriaee A. Numerical simulation of laminar and turbulent two-phase flow in pressure-swirl atomizers. AIAA J., vol. 50, no. 10, 2012, pp. 2091-2101.

[2] Beck J.C., Watkins A.P. On the Development of a Spray Model based on Drop-Size Moments. Proc. R. Soc., Series A, vol. 459, no. 2034, 2003, pp. 1365-1394.

[3] Tukmakov A.L., Tukmakova N.A. Dynamics of a polydisperse vapor mixture with account of crushing, coagulation, evaporation of drops, and condensation of vapor. TVT, vol. 57, no. 3, 2019, pp. 437-445.

[4] Balakhanov D.M. Metrological support for measurements of the disperse parameters of aerosols, suspensions, and powdered materials. Al'manac of Modern Metrology, no. 1 (6), 2016, pp. 87-97.

[5] Julanov Yu.V, Lushnikov A.A., Zagaynov V.A. Diffusion aerosol spectrometer. Atmospheric Research, vol. 62, 2002, pp. 295-302.

[6] Barai N., Mandal N. Breakup versus coalescence of closely packed fluid drops in simple shear flows. Int. J. Multiphase Flow, vol. 111, 2019, pp. 1-15.

[7] Khmelev V.N., Shalunov A.V., Barsukov R.V., Slivin A.N., Tsyganok S.N., Levin S.V., Demidova T.A. Automation of Advanced Cavitation Mode Obtaining Process in Liquid Mediums. Siberian Russian Workshops and Tutorials on Electron Devices and Materials, 2003, Novosibirsk, pp. 222226.

[8] Kharkov V.V. Mathematical modelling of thermolabile solutions concentration in vortex chamber. J. Phys. Conf. Ser., vol. 980, no. 1, 2018, p. 012006. 
[9] Pavlov I.N., Rinkevichyus B.S., Tolkachev A.V. A Setup for Visualizing the Evaporation of a Liquid Drop Using the Method of Frustrated Total Internal Reflection of a Laser Beam. Instruments and Experimental Techniques, vol. 56, no. 2, 2013, pp. 242-246.

[10] Ivanov V.Yu., Baranova A.A., Speranskaya A.A., Gantseva E.N. Automation of the cell counting process in the Goryaev chamber. Materials of the $\mathrm{X}$ International Scientific and Practical conference, 2008, p. 384-388.

[11] Ivanov B.L., Ziganshin B.G., Dmitriev A.V., Lushnov M.A. and Binelo M.O. Numerical modeling of the effect of energy-separation in the Ranque-hilsch tube. International Scientific-Practical Conference "Agriculture and Food Security: Technology, Innovation, Markets, Human Resources". BIO Web Conf., vol. 27, 2020, p. 00109.

[12] Akhalaia, B.H., Shogenov Y.K., The turbulent airstream influence on the seeding quality, Bulletin of the Russian agricultural Science, no. 1, 2018, pp. 54-57.

[13] Sabirov R., Valiev A., Karimova L., Dmitriev A., Khaliullin D. Influence of physical factors on viability of microorganisms for plant protection. 18th International Scientific Conference Engineering For Rural Development Proceedings, May 22-24, Latvia, University of Life Sciences and Technologies Faculty of Engineering, Jelgava, 2019, pp. 555-562.

[14] Kharkov, V.V. Mathematical modelling of thermolabile solutions concentration in vortex chamber/V. V. Kharkov // Journal of Physics: Conf. Ser. - 2018. - Vol. 980. - p. 012006.

[15] Ivanov B.L., Ziganshin B.G., Rudakov A.I., Lushnov M.A. Evaluation of the distribution of drops of disinfectant liquid on the treated surface, Bulletin of the Kazan State Agrarian University, vol. 14, no. 3 (54), 2019, pp. 103-107.

[16] Ivanov B.L., Ziganshin B.G., Sharafeev R.F., Sagbiev, I.R., The theory of liquid atomization by injectors, Bulletin of the Kazan State Agrarian University, vol. 14, no. 2 (53), 2019, pp. 95-99. 